\title{
More than a simple biomarker : Role of NGAL in cardiovascular and renal diseases
}

Mathieu Buonafine, ${ }^{1}$ Ernesto Martinez-Martinez and Frédéric Jaisser ${ }^{1,2}$

${ }^{1}$ INSERM, UMRS 1138, Centre de Recherche des Cordeliers, Pierre et Marie Curie

University, Paris Descartes University, Paris, France.

${ }^{2}$ INSERM, Clinical Investigation Centre 1433, French-Clinical Research Infrastructure Network (F-CRIN) INI-CRCT, RHU Fight-HF, Nancy, France

Word count: 4945

Abstract: 113 words

References: 124

Figures/Tables: 4 


\begin{abstract}
Neutrophil Gelatinase-Associated Lipocalin (NGAL) is a small circulating protein that is induced in a wide variety of pathological situations, making it an interesting biomarker of various disease states. It is considered as one of the best markers of acute kidney injury, since it is rapidly released after tubular damage. However, a growing body of evidence points toward an implication of NGAL beyond its role as a biomarker. Indeed, numerous studies have demonstrated a role for NGAL in the mediation of both cardiovascular and renal diseases. In the present review, we summarize what is known about NGAL involvement in cardiovascular and renal diseases and discuss the different mechanisms underlying its pathological implications.
\end{abstract}




\section{INTRODUCTION}

Neutrophil Gelatinase-Associated Lipocalin (NGAL) (also known as lipocalin-2, $24 \mathrm{p} 3$, siderocalin or uterocalin) is a small secreted glycoprotein of $25 \mathrm{kDa}$. NGAL has been initially identified in mature neutrophil granules (1) but has since been described in many other cell types. NGAL is expressed in renal (2), endothelial (3), liver (4), and smooth muscle cells (SMCs) (5) as well as in cardiomyocytes (6), neurons (7), and in different populations of immune cells such as macrophages $(5,8)$ and dendritic cells (9).

Several roles have been ascribed to NGAL, including iron trafficking (10), chemotactic $(11,12)$ and bacteriostatic (13) effects as well as activities as differentiation, proliferation and growth factor (14). NGAL effects are mediated through two different receptors, $24 \mathrm{p} 3 \mathrm{R}$ and megalin, depending on the tissue. NGAL is used as a biomarker of renal injury because it is rapidly released in response to tubular damage $(15,16)$. However, numerous studies indicate that NGAL is more than a simple biomarker, and that it plays an important role in the pathophysiology of renal as well as cardiovascular diseases. Moreover, NGAL has been involved in various deleterious process such as inflammation and fibrosis.

\section{The lipocalin family}

NGAL is part of the lipocalin protein family. This family includes many small proteins, the majority of which act as transporters, mainly for lipophilic substances. However, other roles for these proteins have been discovered, such as regulation of cell division, differentiation, cell-cell adhesion and cell survival (17). Unlike most protein families whose members are identified on the basis of similarities in their amino acid sequences, members of the lipocalin family share a common three-dimensional structure necessary for their transport function: the lipocalin fold. This structure is composed of eight anti-parallel sheets forming a 
cup-shaped cavity that serve as ligand binding site (Figure 1) (17,18). Differences in amino acid sequences between members of the lipocalin family can be very large (up to $80 \%$ ), allowing a wide variety of ligands within the family $(17,18)$. However, three particular domains are very well preserved and distinguish two branches of lipocalins: the "Kernel", that have three preserved domains (such as NGAL) and the "Outliers" that only have two. (Figure 1) $(17,18)$.

\section{Structure of NGAL}

Like other members of the lipocalin family, NGAL has a three-dimensional barrel structure. Its binding site, however, has two particularities: it is polar and wide enough to bind to certain proteins (13). In addition, the presence of a cysteine residue in position 87 allows NGAL to form a disulfide bridge with a specific ligand, the Matrix Metalloproteinase 9 (MMP-9 also known as gelatinase B) (19), a protein whose enzymatic action allows the degradation of certain extracellular matrix (ECM) components and is therefore involved in tissue remodeling mechanisms (20). The binding of MMP-9 to NGAL does not modify its activity but stabilizes the protein and decreases its degradation (19). The cysteine 87 residue present in humans is absent in rodents, suggesting that NGAL/MMP-9 interaction is not possible in rodents. However, some studies suggest the opposite. Indeed, NGAL was detected in a complex with MMP-9 in the supernatant of a culture of rat SMCs (21) and co-localized with MMP-9 in mouse atheroma plaques (22). In addition, in a mouse breast cancer model, mice genetically invalidated for NGAL exhibited reduced plasma MMP-9 activity compared to Wild Type (WT) mice, illustrating a functional relationship between NGAL and MMP-9 (23).

Apart from MMP-9, NGAL is also able to interact with other ligands, in particular with certain bacterial siderophores (Figure 2). 


\section{Roles of NGAL}

\section{Role of NGAL in iron binding and modulation}

As mentioned above, NGAL is involved in antibacterial defense through iron sequestration. Iron is an essential element for the development of bacteria, but is present in very small quantities in the body. To capture iron from the host, bacteria release proteins with high affinity for iron, i.e. siderophores. In vitro studies have shown that NGAL is able of binding to bacterial siderophores, thus playing a bacteriostatic role in reducing the availability of iron for bacteria (13). In addition, a study using a mouse model with genetic invalidation of NGAL (NGAL KO) showed that these mice had increased susceptibility to bacterial infections (24).

NGAL is also able to bind endogenous siderophores present in humans, i.e. the catechols. This suggests a role of NGAL in iron homeostasis, even in the absence of bacterial infection (10). When NGAL binds to an iron-coupled siderophore (holo-NGAL form), it will transport iron within the cell and thus increase the cytosolic iron concentration (Figure 3A). Conversely, when it is free (apo-NGAL form), it will allow the capture of intracellular iron and its transport to extracellular space, thus inducing a decrease in intracellular iron concentration (Figure 3B) (25). This role of NGAL in iron homeostasis could have a significant impact on pathology since iron levels are important in various deleterious mechanisms such as oxidative stress (26), inflammation (27), apoptosis $(26,28)$ and fibrosis (28).

Chemotactic Role of NGAL 
NGAL has pro-inflammatory and chemotactic roles. The migration of neutrophils in culture is induced by treatment with recombinant NGAL $(11,12)$. In addition, neutrophils from NGAL KO mice have reduced chemotactic properties and adhesion capabilities (11). In a mouse model of psoriasis (inflammatory skin disease), neutrophil infiltration into the dermis was reduced in mice treated with an anti-NGAL antibody and increased by in vivo treatment with recombinant NGAL (12). The recruitment of immune cells in the heart of mice subjected to an ischemia/reperfusion (I/R) episode was blunted in NGAL KO mice (29). When hearts from NGAL KO mice were transplanted into WT recipients, a significant decrease in granulocyte infiltration was observed compared to a WT to WT heart transplant (29). Numerous experiments carried out in cellular and murine cancer models have also demonstrated a role of NGAL in cell migration and invasion (30-32).

Role of NGAL in differentiation, proliferation and as growth factor

NGAL has also been shown to promote differentiation and proliferation, acting as a growth factor (14). Indeed, NGAL stimulates the proliferation and epithelial differentiation of rat embryonic kidney cells and is able to induce the tubular organization of mouse epithelial cells in culture (33). NGAL also induces the proliferation of human vascular SMCs (34) and cardiac fibroblasts (Buonafine et al. [unpublished]). The role of NGAL in cell proliferation has also been demonstrated in gastric and thyroid cancer models $(35,36)$. NGAL participates to the epithelial-mesenchymal transition (EMT) in vivo in a pulmonary adenocarcinoma model in mice (37) and in vitro in prostate (30) and breast cancer cells (38). In these models, NGAL promoted the motility, invasiveness and metastatic capacities of cancer cells.

\section{NGAL receptors}




\section{4 p 3 Receptor}

The $24 \mathrm{p} 3$ receptor $(24 \mathrm{p} 3 \mathrm{R})$ is one of the two receptors currently described for NGAL. $24 \mathrm{p} 3 \mathrm{R}$ is an endocytic receptor with a strong affinity for NGAL which allows it to penetrate inside the cells. It participates to the control of iron homeostasis by allowing NGAL to enter the cells, thus modulating the amount of intracellular iron. The expression of this receptor has been identified in different tissues and notably in the heart (25). Under inflammatory conditions, $24 \mathrm{p} 3 \mathrm{R}$ is expressed in the whole cardiac tissue and, in particular, on the surface of cardiomyocytes (39). In addition, 24p3R is expressed in the renal distal nephron (40) and is involved in albumin endocytosis and activation of pro-inflammatory and pro-fibrotic signaling pathways of NF- $\mathrm{BB}$ and TGF- $\beta$ (41). $24 \mathrm{p} 3 \mathrm{R}$ expression was found to be increased on the surface of neutrophils of patients with psoriasis (12). Finally, the use of an anti-24p3R siRNA has also highlighted the important role of this receptor in the activation of neutrophils by NGAL in culture (12).

\section{Megalin}

The other known receptor for NGAL is megalin (or low-density lipoprotein receptorrelated protein 2, LRP2). Megalin is a multi-ligand endocytic receptor which is expressed in various epithelia and in particular in epithelia with high absorptive capacity such as the epithelium of the renal tubule, ileum, or choroid plexus in the brain (42). Megalin has also been detected in cardiomyocytes cultured in vitro (43) as well as in different types of immune

cells such as T-cells, B-cells, granulocytes and monocytes/macrophages (44). Megalin belongs to the family of low-density lipoprotein receptors (45) and has been shown to bind to various lipocalins $(18,46)$. However, its affinity for NGAL is higher than for other lipocalins (47). The pathophysiological role of the NGAL-megalin complex is still not well described. 


\section{Involvement of NGAL in renal pathologies}

NGAL has been described as an acute renal lesion biomarker because it is rapidly released in response to tubular damage $(15,16)$. NGAL is a secreted protein and can be quantified in plasma or serum. In healthy humans, plasma concentration of NGAL is approximately $70 \mathrm{ng} / \mathrm{mL}$ (48) and about $100 \mathrm{ng} / \mathrm{mL}$ in mice $(8,49)$. NGAL levels analysis is also possible in urine (50). These elements, combined with its good stability and resistance to proteases, make it a biomarker of choice for clinical use $(15,16)$. Creatinine plasma levels are commonly used to evaluate renal function. However, an ever-growing number of studies describe NGAL as a better marker of acute kidney injury (AKI).

\section{NGAL in AKI}

In animals, ischemia/reperfusion (I/R) induces a massive increase in renal NGAL levels within 3 hours after ischemia, while the increase in serum creatinine is still mild (51). In addition, serum creatinine concentration increases after severe bilateral ischemia but remains unchanged after mild bilateral or unilateral ischemia (51). In AKI, NGAL levels are increased up to 300 times in blood $(0.1$ to $30 \mu \mathrm{g} / \mathrm{mL})$ and 1000 times in urine $(0.04$ to 40 $\mathrm{mg} / \mathrm{mL})(49,51)$.

In patients with AKI, the relative level of serum NGAL was correlated with the severity of renal damage and high levels of serum NGAL were associated with an increased risk of mortality (52). In addition, urinary and serum NGAL concentrations have been described as a sensitive, specific and highly predictive markers of AKI after cardiac surgery (50). Several studies have also suggested NGAL as a marker of renal damage in broader pathological contexts than renal ischemia such as glomerulonephritis and $\operatorname{IgA}$ nephropathy $(53,54)$. 
Using a mouse model expressing a bioluminescent reporter of NGAL expression, Paragas et al. have studied the origin of NGAL during AKI. They determined that during I/R, NGAL was synthetized by cells of the thick ascending limb of Henle's loop and of the collecting duct and only in ischemic areas of the kidney (55). In addition, by performing kidney transplants between WT and NGAL KO mice, Paragas et al. demonstrated that the increase in urinary NGAL concentration during renal ischemia was mainly due to the release of NGAL originating in the kidney and that the contribution of extra-renal NGAL to urinary NGAL was small (55).

Another suggested source of urinary NGAL, especially in non-renal diseases, could be circulating NGAL from extra renal origin, being released in the systemic circulation at sites of inflammation, notably by immune cells (56), and then filtered by the renal glomerulus. The majority of NGAL would then be reabsorbed by the proximal tubule, which expresses megalin, and the remaining NGAL would be excreted in the urine. This last point is illustrated, for example, by a study showing that mice deficient in megalin show a leakage of NGAL in the urine (47).

Beyond its role as a biomarker, NGAL is actively involved in the mechanisms underlying kidney damages. NGAL has been shown to play a protective role in AKI after an episode of I/R (49,57). During an I/R episode, the release of large amounts of iron at the time of ischemia promotes oxidative stress and induction of tissue damage. In addition, the subsequent reperfusion further increases the amount of iron, exacerbating the damage caused by oxidative stress $(58,59)$. In animal models, the use of iron-binding protein $(60,61)$, including the injection of recombinant NGAL $(49,57)$, has been shown to limit early damage caused by I/R or rejection of the graft during renal transplantation (62). A study also showed that intravenous injection of macrophages over-expressing the anti-inflammatory cytokine IL- 
10 was able to protect against renal ischemia in rats and improve cell regeneration and tissue repair through the induction of NGAL (63). When rats were treated with an anti-NGAL antibody, the protective role of the adoptive transfer of macrophages over-expressing IL10 was lost (63), underlying a crucial role of NGAL. More recently, a study showed that the infusion of macrophages overexpressing NGAL could improve renal fibrosis in a unilateral ureteral obstruction model in mice (64).

\section{$N G A L$ in $C K D$}

In contrast to its protective effect in AKI, NGAL is described to be harmful in the long term. NGAL is considered as a pro-inflammatory factor that promotes the progression toward CKD $(65,66)$. A high level of urinary NGAL was associated with a higher risk of CKD $(66,67)$. In CKD patients $(66,68)$ or in mouse models of CKD $(65,66)$, NGAL levels were increased and correlated with the severity of renal injury.

The role of NGAL in CKD has been investigated in animal models, particularly using NGAL KO mice. In an anti-glomerular basement membrane antibody-induced glomerulonephritis, NGAL gene invalidation protected mice from proteinuria and tubular lesions while the addition of recombinant NGAL exacerbated kidney disease and decreased survival (65). Similarly, in a subtotal nephrectomy-induced CKD model, NGAL KO mice exhibited less apoptosis, less renal lesions (glomerulosclerosis, tubular atrophy, interstitial fibrosis, immune infiltration), less proteinuria and better renal function than WT mice (66). Interestingly, this study also showed that NGAL was an effector of the proliferative effects of EGFR (Epidermal Growth Factor Receptor) (66) which is known to play an important role in the progression of CKD (69).

In conclusion, the role of NGAL in kidney disease seems to depend on the associated pathological mechanisms: after an acute kidney injury, NGAL plays a protective role, notably 
via its iron-modulating effects, whereas in a more chronic context, its pro-inflammatory and proliferative effects make it a harmful actor.

\section{Involvement of NGAL in cardiovascular diseases}

Besides its role as a biomarker of kidney lesion and its implication in the pathophysiology of renal diseases, NGAL has also been shown to be involved in the development of cardiovascular (CV) diseases.

\section{NGAL in myocardial infarction and heart failure}

Several studies have documented elevated circulating NGAL levels in patients with CV disease (70,71). In patients with acute myocardial infarction (MI) or chronic heart failure (HF), serum NGAL levels are higher than in healthy subjects (70,72). Plasma NGAL levels are higher in MI patients than in patients with stable coronary heart disease (73). Some studies suggest that NGAL may have prognostic value in HF patients because high levels of plasma or urinary NGAL are associated with more renal complications $(70,72,74)$ or mortality $(75-$ 77). In a 10-year follow-up study of healthy subjects, a higher basal level of NGAL was associated with an increase in the proportion of adverse cardiac events and overall mortality from all causes (78). These high levels of NGAL may be explained in part by the renal failure observed in a large number of HF patients (79). However, several studies have showed that NGAL was a predictor of CV incident even in the absence of renal dysfunction (80-82). Circulating NGAL levels have also been described as predictors of CV complications in patients with CKD $(83,84)$. 
In animals, NGAL production is increased in the heart and aorta after MI $(22,72)$. NGAL production is also increased in isolated rat cardiomyocytes in response to stimulation by different pro-inflammatory molecules such as endothelin 1, IL-1 and TNF- $\alpha$ (72). In a recent study from our laboratory, we demonstrated an important role of NGAL in the pathophysiological mechanisms of MI. NGAL KO mice showed decreased cardiac fibrosis and inflammation as well as preserved cardiac function 3 months after MI $(85,86)$. A recent study from Sung et al. using a similar MI model showed that NGAL KO mice exhibited an increase in autophagy associated with decreased apoptosis and preserved cardiac function after infarction (87).

\section{NGAL in atherosclerosis}

In arteries of atherosclerotic patients, NGAL expression was observed in endothelial cells, SMCs and macrophages and was detected at a higher rate in patients with symptomatic carotid stenosis compared to asymptomatic patients (5). The level of circulating NGAL was also associated with plaque vulnerability (88). In a mouse atherosclerosis model, NGAL expression was co-localized with macrophages and MMP-9 in the atherosclerotic plaques, suggesting a possible role of NGAL in MMP-9-mediated remodeling (22).

\section{NGAL in cardiovascular ischemia}

The role of NGAL has also been shown in the cardiac lesions induced by I/R $(89,90)$. After an episode of $\mathrm{I} / \mathrm{R}$, in a model of isolated-perfused heart, NGAL KO heart exhibited a reduced infarct size and better cardiac contractile function than the WT heart (90). In addition, increasing NGAL circulating levels of NGAL KO mice using an NGAL encoding adenovirus treatment resulted in impaired cardiac functional recovery and decreased mitochondrial function of the isolated-perfused hearts (90). In a mouse model of $\mathrm{I} / \mathrm{R}$ after heart 
transplantation, the use of anti-NGAL antibodies reduced the infiltration of macrophages and neutrophils into the ischemic zone, suppressed the M1 polarization of macrophages, and blunted the I/R-induced cardiac lesions (89).

In a rat model of cerebrovascular ischemia, a large increase of NGAL and MMP-9 was found in the intima of the common carotid artery (21). In this model, blocking the NF- $\mathrm{BB}$ pathway in vivo led to an almost total suppression of NGAL and MMP-9 expression, suggesting a central role of NF- $\mathrm{B}$ signaling in NGAL and MMP-9 transcriptional regulation in this context (21). In vitro, expression of NGAL in cultured SMCs was also induced in an NF- $\kappa \mathrm{B}$ dependent manner by treatment with IL-1 $\beta$ (21).

\section{NGAL in abdominal aortic aneurysm}

Biopsy analysis of patients with abdominal aortic aneurysm (AAA) identified the expression of the NGAL/MMP-9 complex in the vascular wall and in the thrombus present in the blood vessel lumen (91). Neutrophils were the major source of NGAL expression in this context. In an AAA model in mice, the absence of NGAL (in NGAL KO mice) or its blockade (with anti-NGAL antibodies) had the same protective effects against AAA development, with a decrease in neutrophil infiltration and MMP activity (92).

\section{NGAL in cardiometabolic disorders}

In obesity in humans and animals, circulating NGAL levels are increased and correlated with increases in blood pressure and insulin resistance (93). A recent study from our laboratory also reported an increase in plasma levels of the NGAL/MMP-9 complex in a cohort of obese patients correlated with an increase in circulating fibrosis markers (94).

In animal models of obesity, NGAL KO mice were protected against hypertension (95), inflammation $(95,96)$ as well as endothelial (97) and cardiometabolic dysfonctions 
$(90,96,97)$ induced by a high fat diet. Song et al. reported that the deamidation of NGAL (by linoleic acid in particular) improved its stability and promoted its accumulation (95). The combined administration of recombinant NGAL and linoleic acid in WT mice promoted oxidative stress, endothelial dysfunction, inflammation and hypertension (95).

\section{NGAL and iron metabolism in cardiomyopathies}

NGAL participated to iron transport by binding a siderophore and can increase or decrease the amount of intracellular iron, thus participating in the maintenance of iron homeostasis. Both iron overload and iron deficiency have been linked to cardiomyopathies: iron overload has been associated with increased oxidative stress and iron deficiency with mitochondrial dysfunction, impaired cardiac function (98), hyper-coagulation and oxidative stress related to anemia (99). The involvement of NGAL in iron homeostasis could therefore play an important role in the development of some cardiomyopathies. Indeed, NGAL has also been shown to participate to cardiomyocyte apoptosis resulting from intracellular iron accumulation (100). The apoptosis of cardiomyocytes could therefore influence the remodeling process involved in the development of certain cardiac pathologies, underlying a potential implication of NGAL in this process.

\section{Involvement of NGAL in inflammatory mechanisms}

NGAL and pro-inflammatory cytokines expression 
In heart failure and various other inflammatory pathologies, serum or plasma levels of NGAL have been shown to correlate with those of other inflammatory markers such as TNF$\alpha$, CRP, IL-6 or leukocytes number $(101,102)$.

NGAL expression can be induced by various pro-inflammatory stimuli, such as LPS (103), IL-1 $\beta$ (104), IL-6 (3), IL-17 (105), IFN- $\gamma$ (106) and TNF- $\alpha$ (72) depending on cell type. Furthermore, NGAL expression is positively regulated by the activation of the NF- $\kappa \mathrm{B}$ pathway (21) which is known for its role in pro-inflammatory mechanisms. Conversely, NGAL is able to activate the NF- $\kappa \mathrm{B}$ pathway $(107,108)$ and to induce the expression of diverse pro-inflammatory molecules such as IL-8 $(5,12)$, IL-6 (5,12), IL1- $\alpha$ (12), TNF- $\alpha(12)$ and MCP-1 (5). Finally, it has been shown that NGAL was involved in the polarization of macrophages towards the pro-inflammatory phenotype M1, in vitro and in vivo $(89,109)$.

Altogether these data suggest the existence of a vicious circle in which NGAL is overexpressed in inflammatory conditions and capable, in turn, to potentiate inflammation by inducing the expression of pro-inflammatory mediators (Figure 4).

\section{NGAL and inflammatory diseases}

NGAL is proposed to be involved in chronic inflammation and autoimmune diseases. Urinary levels of NGAL were increased in patients with lupus nephropathy and were associated with the severity of the disease (110). In a rat autoimmune myocarditis model, NGAL was strongly expressed in cardiomyocytes, vascular SMCs, fibroblasts and neutrophils (39). In addition, increased NGAL levels were particularly important during the active phase of myocarditis and closely followed cardiac and plasma IL-1 $\beta$ levels (39). In an acute antibody-induced skin inflammation model, NGAL KO mice showed a 50\% reduction in inflammation associated with reduced immune infiltration compared to WT mice (111). The 
same benefit was found by injecting WT mice with anti-NGAL antibodies while inflammation was restored by treatment with recombinant NGAL (111).

\section{NGAL expression by immune cells}

NGAL expression was first described in neutrophils (1) and later observed in other immune cell types such as macrophages $(5,8)$ and dendritic cells (9). Recent studies suggest that the expression of NGAL by these immune cell types could be important in the regulation of inflammatory processes. It has been shown, for instance, that NGAL secreted by dendritic cells was involved in the activation and polarization of T-cells toward a pro-inflammatory phenotype (9). Gilet et al. showed that aldosterone was able to induce the production of NGAL by human neutrophils in complex with MMP-9 (112). Aigner et al. identified neutrophils as the primary source of NGAL released at the time of immune infiltration in the mouse heart after an episode of I/R (29).

A recent study from our laboratory, using mice depleted from NGAL in their immune cells only (after bone marrow transplantation), allowed us to demonstrate the pivotal role of NGAL produced by immune cells in the cardiac and renal deleterious effects of a mineralocorticoid challenge (Buonafine et al. [unpublished]). In WT mice, this challenge induced systemic inflammation and an induction of NGAL expression by macrophages, dendritic cells, and peripheral blood mononuclear cells (PBMCs). The depletion of NGAL from immune cells protected the mice against cardiac and renal remodeling as well as inflammation induced by mineralocorticoid excess (Buonafine et al. [unpublished]). Of note, mice depleted of NGAL in their immune cells presented lower levels of cardiac NGAL compared to control mice, revealing immune cells as a major source of NGAL in the heart (Buonafine et al. [unpublished]). 


\section{Involvement of NGAL in hypertensive mechanisms}

In patients with essential hypertension, plasma NGAL level were higher than in healthy subjects and correlated with blood pressure (113). In clinical studies, polymorphisms in the promoter of NGAL have been associated with changes in blood pressure (114).

The role of NGAL in hypertensive mechanisms was also demonstrated in animal models of obesity. NGAL KO mice were protected against hypertension, inflammation and cardiometabolic dysfunction induced by a high fat diet (95-97). The direct role of NGAL in blood pressure control was further demonstrated by the combined administration of recombinant NGAL and linoleic acid in mice, which induced an increase in mouse blood pressure (95). Recently, a study from our laboratory demonstrated the crucial role of NGAL in the setting of aldosterone-mediated hypertension. Indeed, the global genetic inactivation of NGAL in mice prevented the increase in blood pressure induced by a mineralocorticoid challenge (94).

\section{Involvement of NGAL in pro-fibrotic mechanisms}

The role of NGAL in pro-fibrotic mechanisms was first suggested by the identification of its binding to MMP-9, a protein involved in extracellular matrix remodeling (19). Our laboratory demonstrated recently the crucial role of NGAL in the pro-fibrotic effects of a mineralocorticoid challenge (94) and in a model of MI (85).

The mechanisms by which NGAL induces fibrosis are probably diverse. NGAL binding to MMP-9 may be one, although the existence of NGAL/MMP-9 in rodents remains controversial. It is also possible that NGAL binds to other molecules able of modulating fibrosis. For example, NGAL binds and negatively regulates the activity of HGF (Hepatocyte Growth Factor), a peptide known for its anti-fibrotic properties (115). We recently showed a direct pro-fibrotic role of NGAL in human cardiac fibroblasts ((85); Buonafine et al. 
[unpublished]). The treatment of fibroblasts with aldosterone induced the expression of NGAL and collagen I. However, inhibition of NGAL expression by siRNA resulted in the loss of induction of collagen I expression by aldosterone. This suggests that NGAL could act as a mediator of the pro-fibrotic effects of aldosterone in vivo (85).

In addition, our data indicate that NGAL has an effect on the proliferation of fibroblasts in vitro (Buonafine et al. [unpublished]). This proliferative effect of NGAL was also described in vivo in renal I/R models in which recombinant NGAL injection induced tubular cell proliferation $(49,57)$ while NGAL KO mice had reduced tubular proliferation in a mouse model of CKD (66). Given the key role of proliferation (of myofibroblastes in particular) in the mechanisms of remodeling and fibrosis (116), the proliferative effects of NGAL could also be implicated in pathological organ remodeling.

\section{Signaling pathways involved in the pathological effects of NGAL}

\section{Erk1/2 signaling pathway}

Another signaling pathway modulated by NGAL is the ERK1/2 pathway. This signaling pathway is known for its involvement in cell proliferation and cell death processes (117). Aldosterone has been shown to induce NGAL/MMP-9 in human neutrophils in culture, and this effect was prevented by the use of an ERK1/2 inhibitor (112). The role of the ERK1/2 pathway in the induction of NGAL has also been described in intestinal epithelial cells in response to a bacterial toxin (118). It is interesting to note that expression of the NGAL receptor $24 \mathrm{p} 3 \mathrm{R}$ was induced by IL-1 $\beta$ in human mesangial cells in culture and also involved activation of the ERK1/2 signaling pathway (119). Conversely, several studies have shown that NGAL is able to activate the ERK1/2 signaling pathway and that this pathway is involved in the cellular effects of NGAL. Treatment of cultured epithelial cells with NGAL 
induced activation of the ERK1/2 pathway and induced cell migration, which was lost through inhibition of this signaling pathway (33). Similarly, the treatment of human neutrophils in culture with recombinant NGAL stimulated cell migration and proinflammatory cytokine expression via the $24 \mathrm{p} 3 \mathrm{R}$ receptor and induction of the ERK1/2 signaling pathway (12). In models of esophageal (31) or prostate cancer cells (120), overexpression of NGAL or treatment with recombinant NGAL activated the ERK1/2 pathway and blocking this pathway blocked the migration and invasive properties of the cells promoted by NGAL.

\section{$N F \kappa B$ signaling pathway}

A large number of studies have shown that the NF- $\kappa \mathrm{B}$ pathway controls the expression of NGAL $(4,21,35,36)$. Conversely, some studies have shown that NGAL itself is capable of

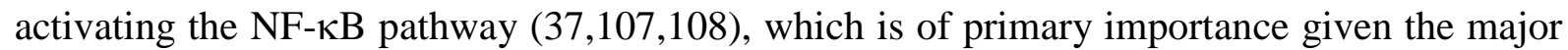
involvement of this pathway in inflammatory and fibrotic mechanisms $(121,122)$. In a cell model with NGAL overexpression, Wang et al. showed, for example, that NGAL activated the NF- $\kappa \mathrm{B}$ pathway via increased levels of intracellular iron and reactive oxygen species

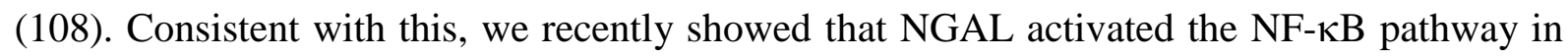
cardiac cells, in vivo and in vitro (85). The treatment of cardiac fibroblasts with recombinant NGAL induced NF- $\kappa \mathrm{B}$ activation while blocking the NF- $\kappa \mathrm{B}$ pathway prevented NGALinduced production of collagen I (85). The NF- $\kappa \mathrm{B}$ pathway was activated in WT mice seven days after MI, but this was not the case in NGAL KO mice, demonstrating the importance of NGAL in activating this pathway in vivo (85). These findings highlight the importance of the $\mathrm{NF}-\kappa \mathrm{B}$ pathway in mediating the direct pro-fibrotic effects of NGAL. 


\section{CONCLUSION}

In conclusion, NGAL appears to be an important mediator of cardiac and renal diseases through its role in hypertensive, inflammatory and fibrotic processes. High levels of NGAL are reported in a wide variety of pathological situations, both in animals and in patients, and NGAL blockade using neutralizing antibodies or genetic inactivation is beneficial in animal models of cardiac or renal injuries. The role of NGAL in inflammation is of particular importance since NGAL is part of a pro-inflammatory amplification loop. NGAL is induced in inflammatory situations and is able to amplify inflammation, by the production of pro-inflammatory cytokines, the activation of pro-inflammatory pathways as well as the polarization of immune cells toward pro-inflammatory phenotypes. This pro-inflammatory role of NGAL could be important in the mediation of its hypertensive and fibrotic effects, since the interconnection of these pathological mechanisms is now well described (123-125). Finally, NGAL production and secretion by immune cells themselves seem to play an important role in some cardiorenal pathological situations. The role of NGAL produced by specific immune cell populations should thus be further studied.

Given the importance of its pathological implications, NGAL could represent an interesting therapeutic target in $\mathrm{CV}$ and renal diseases and beyond, especially in pathologies involving inflammatory mechanisms. 


\section{Disclosure}

FJ received research grants from BAYER Pharma AG.

\section{Funding}

This work was funded by grants from the Institut National de la Santé et de la Recherche Médicale, ANR MRFOCUS (ANR-15-CE14-0032-02), the Fight-HF Avenir investment program (ANR-15-RHUS-0004). MB was supported by a PhD grant from Region Ile de France CORDDIM. 


\section{REFERENCES}

1. Kjeldsen L, Johnsen AH, Sengelov H, Borregaard N. Isolation and primary structure of NGAL, a novel protein associated with human neutrophil gelatinase. J Biol Chem. 1993;268:10425-32.

2. Liu F, Yang H, Chen H, Zhang M, Ma Q. High expression of neutrophil gelatinaseassociated lipocalin (NGAL) in the kidney proximal tubules of diabetic rats. Adv Med Sci. 2015 Mar;60(1):133-8.

3. Hamzic N, Blomqvist A, Nilsberth C. Immune-Induced Expression of Lipocalin-2 in Brain Endothelial Cells: Relationship with Interleukin-6, Cyclooxygenase-2 and the Febrile Response. J Neuroendocrinol. 2013 Mar;25(3):271-80.

4. Borkham-Kamphorst E, Drews F, Weiskirchen R. Induction of lipocalin-2 expression in acute and chronic experimental liver injury moderated by pro-inflammatory cytokines interleukin- $1 \beta$ through nuclear factor- $\kappa \mathrm{B}$ activation: LCN2 induction in acute and chronic experimental liver injury. Liver Int. 2011 May;31(5):656-65.

5. Eilenberg W, Stojkovic S, Piechota-Polanczyk A, Kaun C, Rauscher S, Gröger M, et al. Neutrophil Gelatinase-Associated Lipocalin (NGAL) is Associated with Symptomatic Carotid Atherosclerosis and Drives Pro-inflammatory State In Vitro. Eur J Vasc Endovasc Surg. 2016 May;51(5):623-31.

6. Latouche C, El Moghrabi S, Messaoudi S, Nguyen Dinh Cat A, Hernandez-Diaz I, Alvarez de la Rosa D, et al. Neutrophil gelatinase-associated lipocalin is a novel mineralocorticoid target in the cardiovascular system. Hypertension. 2012 May;59(5):966-72. 7. Naudé PJW, Eisel ULM, Comijs HC, Groenewold NA, De Deyn PP, Bosker FJ, et al. Neutrophil gelatinase-associated lipocalin: A novel inflammatory marker associated with latelife depression. J Psychosom Res. 2013 Nov;75(5):444-50.

8. Flo TH, Smith KD, Sato S, Rodriguez DJ, Holmes MA, Strong RK, et al. Lipocalin 2 mediates an innate immune response to bacterial infection by sequestrating iron. Nature. 2004 Dec 16;432(7019):917-21.

9. Floderer M, Prchal-Murphy M, Vizzardelli C. Dendritic Cell-Secreted Lipocalin2 Induces CD8+ T-Cell Apoptosis, Contributes to T-Cell Priming and Leads to a TH1 Phenotype. Appel S, editor. PLoS ONE. 2014 Jul 10;9(7):e101881.

10. Bao G, Clifton M, Hoette TM, Mori K, Deng S-X, Qiu A, et al. Iron traffics in circulation bound to a siderocalin (Ngal)-catechol complex. Nat Chem Biol. 2010 Aug;6(8):602-9.

11. Schroll A, Eller K, Feistritzer C, Nairz M, Sonnweber T, Moser PA, et al. Lipocalin-2 ameliorates granulocyte functionality: Innate immunity. Eur J Immunol. 2012 Dec;42(12):3346-57.

12. Shao S, Cao T, Jin L, Li B, Fang H, Zhang J, et al. Increased Lipocalin-2 Contributes to the Pathogenesis of Psoriasis by Modulating Neutrophil Chemotaxis and Cytokine Secretion. J Invest Dermatol. 2016 Jul;136(7):1418-28.

13. Goetz DH. The neutrophil lipocalin NGAL is a bacteriostatic agent that interferes with siderophore-mediated iron acquisition. Mol Cell. 2002;10:1033-43.

14. Schmidt-Ott KM, Mori K, Li JY, Kalandadze A, Cohen DJ, Devarajan P, et al. Dual Action of Neutrophil Gelatinase-Associated Lipocalin. J Am Soc Nephrol. 2007 Jan 17;18(2):407-13.

15. Di Grande A, Giuffrida C, Carpinteri G, Narbone G, Pirrone G, Di Mauro A, et al. Neutrophil gelatinase-associated lipocalin: a novel biomarker for the early diagnosis of acute kidney injury in the emergency department. Eur Rev Med Pharmacol Sci. 2009 Jun;13(3):197-200.

16. Parikh CR, Devarajan P. New biomarkers of acute kidney injury. Crit Care Med. 2008 
Apr;36(4 Suppl):S159-165.

17. Chakraborty S, Kaur S, Guha S, Batra SK. The multifaceted roles of neutrophil gelatinase associated lipocalin (NGAL) in inflammation and cancer. Biochim Biophys Acta BBA - Rev Cancer. 2012 Aug;1826(1):129-69.

18. Flower DR. Beyond the superfamily: the lipocalin receptors. Biochim Biophys Acta BBA-Protein Struct Mol Enzymol. 2000;1482(1):327-336.

19. Yan L, Borregaard N, Kjeldsen L, Moses MA. The High Molecular Weight Urinary Matrix Metalloproteinase (MMP) Activity Is a Complex of Gelatinase B/MMP-9 and Neutrophil Gelatinase-associated Lipocalin (NGAL): MODULATION OF MMP-9 ACTIVITY BY NGAL. J Biol Chem. 2001 Oct 5;276(40):37258-65.

20. Yabluchanskiy A, Ma Y, Iyer RP, Hall ME, Lindsey ML. Matrix Metalloproteinase-9: Many Shades of Function in Cardiovascular Disease. Physiology. 2013 Nov;28(6):391-403.

21. Bu D, Hemdahl A-L, Gabrielsen A, Fuxe J, Zhu C, Eriksson P, et al. Induction of Neutrophil Gelatinase-Associated Lipocalin in Vascular Injury via Activation of Nuclear Factor-?B. Am J Pathol. 2006 Dec;169(6):2245-53.

22. Anne-Louise Hemdahl AG. Expression of neutrophil gelatinase-associated lipocalin in atherosclerosis and myocardial infarction. Arterioscler Thromb Vasc Biol. 2006;26(1):13642.

23. Leng X, Ding T, Lin H, Wang Y, Hu L, Hu J, et al. Inhibition of Lipocalin 2 Impairs Breast Tumorigenesis and Metastasis. Cancer Res. 2009 Nov 15;69(22):8579-84.

24. Berger T, Togawa A, Duncan GS, Elia AJ, You-Ten A, Wakeham A, et al. Lipocalin 2-deficient mice exhibit increased sensitivity to Escherichia coli infection but not to ischemiareperfusion injury. Proc Natl Acad Sci U S A. 2006 Feb 7;103(6):1834-9.

25. Devireddy LR, Gazin C, Zhu X, Green MR. A Cell-Surface Receptor for Lipocalin 24p3 Selectively Mediates Apoptosis and Iron Uptake. Cell. 2005 Dec;123(7):1293-305.

26. Wang Y, Wu M, Al-Rousan R, Liu H, Fannin J, Paturi S, et al. Iron-Induced Cardiac Damage: Role of Apoptosis and Deferasirox Intervention. J Pharmacol Exp Ther. 2011 Jan 1;336(1):56-63.

27. Kim J, Wessling-Resnick M. The Role of Iron Metabolism in Lung Inflammation and Injury. J Allergy Ther. 2012 Jan 25;0(0):1-6.

28. Whittaker P, Hines FA, Robl MG, Dunkel VC. Histopathological Evaluation of Liver, Pancreas, Spleen, and Heart from Iron-Overloaded Sprague-Dawley Rats* 1, 2. Toxicol Pathol. 1996;24(5):558-563.

29. Aigner F, Maier HT, Schwelberger HG, Wallnöfer EA, Amberger A, Obrist P, et al. Lipocalin-2 Regulates the Inflammatory Response During Ischemia and Reperfusion of the Transplanted Heart. Am J Transplant. 2007 Apr;7(4):779-88.

30. Ding G, Fang J, Tong S, Qu L, Jiang H, Ding Q, et al. Over-expression of lipocalin 2 promotes cell migration and invasion through activating ERK signaling to increase SLUG expression in prostate cancer: LCN2/ERK/SLUG Axis Promotes PCa Aggression. The Prostate. 2015 Jun;75(9):957-68.

31. Du Z-P, Wu B-L, Xie Y-M, Zhang Y-L, Liao L-D, Zhou F, et al. Lipocalin 2 promotes the migration and invasion of esophageal squamous cell carcinoma cells through a novel positive feedback loop. Biochim Biophys Acta BBA - Mol Cell Res. 2015 Oct;1853(10):2240-50.

32. Leung L, Radulovich N, Zhu C-Q, Organ S, Bandarchi B, Pintilie M, et al. Lipocalin2 Promotes Invasion, Tumorigenicity and Gemcitabine Resistance in Pancreatic Ductal Adenocarcinoma. Schneider G, editor. PLoS ONE. 2012 Oct 4;7(10):e46677.

33. Gwira JA, Wei F, Ishibe S, Ueland JM, Barasch J, Cantley LG. Expression of Neutrophil Gelatinase-associated Lipocalin Regulates Epithelial Morphogenesis in Vitro. J Biol Chem. 2005 Mar 4;280(9):7875-82. 
34. Wang G, Ma N, Meng L, Wei Y, Gui J. Activation of the phosphatidylinositol 3kinase/Akt pathway is involved in lipocalin-2-promoted human pulmonary artery smooth muscle cell proliferation. Mol Cell Biochem. 2015 Dec;410(1-2):207-13.

35. Iannetti A, Pacifico F, Acquaviva R, Lavorgna A, Crescenzi E, Vascotto C, et al. The neutrophil gelatinase-associated lipocalin (NGAL), a NF- $\kappa B$-regulated gene, is a survival factor for thyroid neoplastic cells. Proc Natl Acad Sci. 2008;105(37):14058-14063.

36. Koh SA, Lee KH. HGF mediated upregulation of lipocalin 2 regulates MMP9 through nuclear factor- $\kappa B$ activation. Oncol Rep. 2015 Oct;34(4):2179-87.

37. Mongre RK, Sodhi SS, Sharma N, Ghosh M, Kim JH, Kim N, et al. Epigenetic induction of epithelial to mesenchymal transition by LCN2 mediates metastasis and tumorigenesis, which is abrogated by NF- $\mathrm{BB}$ inhibitor BRM270 in a xenograft model of lung adenocarcinoma. Int J Oncol. 2016 Jan;48(1):84-98.

38. Yang J, Bielenberg DR, Rodig SJ, Doiron R, Clifton MC, Kung AL, et al. Lipocalin 2 promotes breast cancer progression. Proc Natl Acad Sci U S A. 2009 Mar 10;106(10):3913-8. 39. Ding L, Hanawa H, Ota Y, Hasegawa G, Hao K, Asami F, et al. Lipocalin2/Neutrophil Gelatinase-B Associated Lipocalin Is Strongly Induced in Hearts of Rats With Autoimmune Myocarditis and in Human Myocarditis. Circ J. 2010;74(3):523-30.

40. Langelueddecke C, Roussa E, Fenton RA, Wolff NA, Lee W-K, Thevenod F. Lipocalin-2 (24p3/Neutrophil Gelatinase-associated Lipocalin (NGAL)) Receptor Is Expressed in Distal Nephron and Mediates Protein Endocytosis. J Biol Chem. 2012 Jan 2;287(1):159-69.

41. Dizin E, Hasler U, Nlandu-Khodo S, Fila M, Roth I, Ernandez T, et al. Albuminuria induces a proinflammatory and profibrotic response in cortical collecting ducts via the $24 \mathrm{p} 3$ receptor. AJP Ren Physiol. 2013 Oct 1;305(7):F1053-63.

42. Moestrup SK, Verroust PJ. Megalin- and Cubilin-Mediated Endocytosis of ProteinBound Vitamins, Lipids, and Hormones in Polarized Epithelia. Annu Rev Nutr. 2001;21(1):407-28.

43. Van Dijk A, Vermond RA, Krijnen PAJ, Juffermans LJM, Hahn NE, Makker SP, et al. Intravenous clusterin administration reduces myocardial infarct size in rats: CLUSTERIN ADMINISTRATION REDUCES INFARCT SIZE. Eur J Clin Invest. 2010 Oct;40(10):893902.

44. Miharada K, Hiroyama T, Sudo K, Danjo I, Nagasawa T, Nakamura Y. Lipocalin 2mediated growth suppression is evident in human erythroid and monocyte/macrophage lineage cells. J Cell Physiol. 2008 May;215(2):526-37.

45. Saito A, Pietromonaco S, Loo AK-C, Farquhar MG. Complete cloning and sequencing of rat gp330/“ megalin," a distinctive member of the low density lipoprotein receptor gene family. Proc Natl Acad Sci. 1994;91(21):9725-9729.

46. Leheste JR, Rolinski B, Vorum H, Hilpert J, Nykjaer A, Jacobsen C, et al. Megalin knockout mice as an animal model of low molecular weight proteinuria. Am J Pathol. 1999 Oct;155(4):1361-70.

47. Hvidberg V, Jacobsen C, Strong RK, Cowland JB, Moestrup SK, Borregaard N. The endocytic receptor megalin binds the iron transporting neutrophil-gelatinase-associated lipocalin with high affinity and mediates its cellular uptake. FEBS Lett. 2005 Jan 31;579(3):773-7.

48. Axelsson L, Bergenfeldt M, Ohlsson K. Studies of the release and turnover of a human neutrophil lipocalin. Scand J Clin Lab Invest. 1995;55(7):577-588.

49. Mori K, Lee HT, Rapoport D, Drexler IR, Foster K, Yang J, et al. Endocytic delivery of lipocalin-siderophore-iron complex rescues the kidney from ischemia-reperfusion injury. $\mathrm{J}$ Clin Invest. 2005 Mar 1;115(3):610-21.

50. Mishra J, Dent C, Tarabishi R, Mitsnefes MM, Ma Q, Kelly C, et al. Neutrophil 
gelatinase-associated lipocalin (NGAL) as a biomarker for acute renal injury after cardiac surgery. The Lancet. 2005;365(9466):1231-1238.

51. Mishra J. Identification of Neutrophil Gelatinase-Associated Lipocalin as a Novel Early Urinary Biomarker for Ischemic Renal Injury. J Am Soc Nephrol. 2003 Oct $1 ; 14(10): 2534-43$.

52. Kümpers P, Hafer C, Lukasz A, Lichtinghagen R, Brand K, Fliser D, et al. Serum neutrophil gelatinase-associated lipocalin at inception of renal replacement therapy predicts survival in critically ill patients with acute kidney injury. Crit Care. 2010;14(1):R9.

53. Bolignano D, Coppolino G, Lacquaniti A, Nicocia G, Buemi M. Pathological and Prognostic Value of Urinary Neutrophil Gelatinase-Associated Lipocalin in Macroproteinuric Patients with Worsening Renal Function. Kidney Blood Press Res. 2008;31(4):274-9.

54. Ding H, He Y, Li K, Yang J, Li X, Lu R, et al. Urinary neutrophil gelatinaseassociated lipocalin (NGAL) is an early biomarker for renal tubulointerstitial injury in IgA nephropathy. Clin Immunol. 2007 May;123(2):227-34.

55. Paragas N, Qiu A, Zhang Q, Samstein B, Deng S-X, Schmidt-Ott KM, et al. The Ngal reporter mouse detects the response of the kidney to injury in real time. Nat Med. 2011 Feb;17(2):216-22.

56. Kanda J, Mori K, Kawabata H, Kuwabara T, Mori KP, Imamaki H, et al. An AKI biomarker lipocalin 2 in the blood derives from the kidney in renal injury but from neutrophils in normal and infected conditions. Clin Exp Nephrol. 2015 Feb;19(1):99-106. 57. Mishra J. Amelioration of Ischemic Acute Renal Injury by Neutrophil GelatinaseAssociated Lipocalin. J Am Soc Nephrol. 2004 Dec 1;15(12):3073-82.

58. Choi EK, Jung H, Kwak KH, Yi SJ, Lim JA, Park SH, et al. Inhibition of Oxidative Stress in Renal Ischemia-Reperfusion Injury. Anesth Analg. 2017 Jan;124(1):204-13.

59. Sponsel HT, Alfrey AC, Hammond WS, Durr JA, Ray C, Anderson RJ. Effect of iron on renal tubular epithelial cells. Kidney Int. 1996 Aug 1;50(2):436-44.

60. Bernardi RM, Constantino L, Machado RA, Vuolo F, Budni P, Ritter C, et al. Nacetylcysteine and deferrioxamine protects against acute renal failure induced by ischemia/reperfusion in rats. Rev Bras Ter Intensiva. 2012 Sep;24(3):219-23.

61. de Vries B, Walter SJ, von Bonsdorff L, Wolfs TGAM, van Heurn LWE, Parkkinen J, et al. Reduction of circulating redox-active iron by apotransferrin protects against renal ischemia-reperfusion injury. Transplantation. 2004 Mar 15;77(5):669-75.

62. Ashraf MI, Schwelberger HG, Brendel KA, Feurle J, Andrassy J, Kotsch K, et al. Exogenous Lipocalin 2 Ameliorates Acute Rejection in a Mouse Model of Renal Transplantation. Am J Transplant Off J Am Soc Transplant Am Soc Transpl Surg. 2016 Mar;16(3):808-20.

63. Jung M, Sola A, Hughes J, Kluth DC, Vinuesa E, Viñas JL, et al. Infusion of IL-10expressing cells protects against renal ischemia through induction of lipocalin-2. Kidney Int. 2012;81(10):969-982.

64. Guiteras R, Sola A, Flaquer M, Hotter G, Torras J, Grinyó JM, et al. Macrophage Overexpressing NGAL Ameliorated Kidney Fibrosis in the UUO Mice Model. Cell Physiol Biochem Int J Exp Cell Physiol Biochem Pharmacol. 2017 Aug 9;42(5):1945-60.

65. Pawar RD, Pitashny M, Gindea S, Tieng AT, Levine B, Goilav B, et al. Neutrophil gelatinase-associated lipocalin is instrumental in the pathogenesis of antibody-mediated nephritis in mice. Arthritis Rheum. 2012 May;64(5):1620-31.

66. Viau A, El Karoui K, Laouari D, Burtin M, Nguyen C, Mori K, et al. Lipocalin 2 is essential for chronic kidney disease progression in mice and humans. J Clin Invest. 2010 Nov 1;120(11):4065-76.

67. Wu Y, Su T, Yang L, Zhu S-N, Li X-M. Urinary neutrophil gelatinase-associated lipocalin: A potential biomarker for predicting rapid progression of drug-induced chronic 
tubulointerstitial nephritis. Am J Med Sci. 2010 Jun;339(6):537-42.

68. Nickolas TL, Forster CS, Sise ME, Barasch N, Solá-Del Valle D, Viltard M, et al. NGAL (Lcn2) monomer is associated with tubulointerstitial damage in chronic kidney disease. Kidney Int. 2012 Sep;82(6):718-22.

69. Zeng F, Singh AB, Harris RC. The role of the EGF family of ligands and receptors in renal development, physiology and pathophysiology. Exp Cell Res. 2009 Feb;315(4):602-10. 70. Damman K, van Veldhuisen DJ, Navis G, Voors AA, Hillege HL. Urinary neutrophil gelatinase associated lipocalin (NGAL), a marker of tubular damage, is increased in patients with chronic heart failure. Eur J Heart Fail. 2008 Oct;10(10):997-1000.

71. Shrestha K, Borowski AG, Troughton RW, Klein AL, Tang WHW. Association Between Systemic Neutrophil Gelatinase-Associated Lipocalin and Anemia, Relative Hypochromia, and Inflammation in Chronic Systolic Heart Failure: NGAL and anemia in chronic heart failure. Congest Heart Fail. 2012 Sep;18(5):239-44.

72. Yndestad A, Landrø L, Ueland T, Dahl CP, Flo TH, Vinge LE, et al. Increased systemic and myocardial expression of neutrophil gelatinase-associated lipocalin in clinical and experimental heart failure. Eur Heart J. 2009 May;30(10):1229-36.

73. Sahinarslan A, Kocaman SA, Bas D, Akyel A, Ercin U, Zengin O, et al. Plasma neutrophil gelatinase-associated lipocalin levels in acute myocardial infarction and stable coronary artery disease. Coron Artery Dis. 2011 Aug;22(5):333-8.

74. Mortara A, Bonadies M, Mazzetti S, Fracchioni I, Delfino P, Chioffi M, et al. Neutrophil gelatinase-associated lipocalin predicts worsening of renal function in acute heart failure: methodological and clinical issues. J Cardiovasc Med Hagerstown Md. 2013 Sep;14(9):629-34.

75. Bolignano D, Basile G, Parisi P, Coppolino G, Nicocia G, Buemi M. Increased plasma neutrophil gelatinase-associated lipocalin levels predict mortality in elderly patients with chronic heart failure. Rejuvenation Res. 2009 Feb;12(1):7-14.

76. van Deursen VM, Damman K, Voors AA, van der Wal MH, Jaarsma T, van Veldhuisen DJ, et al. Prognostic value of plasma neutrophil gelatinase-associated lipocalin for mortality in patients with heart failure. Circ Heart Fail. 2014;7(1):35-42.

77. Villacorta H, Martins Santos RA, Baco Marroig MA, Guedes Pereira GP, Xavier AR, Kanaan S. Prognostic value of plasma neutrophil gelatinase-associated lipocalin in patients with heart failure. Rev Port Cardiol Engl Ed. 2015 Jul 1;34(7):473-8.

78. Lindberg S, Jensen JS, Mogelvang R, Pedersen SH, Galatius S, Flyvbjerg A, et al. Plasma Neutrophil Gelatinase-Associated Lipocalinin in the General Population Association With Inflammation and Prognosis. Arterioscler Thromb Vasc Biol. 2014;34(9):2135-2142.

79. De Berardinis B, Gaggin HK, Magrini L, Belcher A, Zancla B, Femia A, et al. Comparison between admission natriuretic peptides, NGAL and SST2 testing for the prediction of worsening renal function in patients with acutely decompensated heart failure. Clin Chem Lab Med. 2015 Mar;53(4):613-21.

80. Daniels LB, Barrett-Connor E, Clopton P, Laughlin GA, Ix JH, Maisel AS. Plasma Neutrophil Gelatinase-Associated Lipocalin Is Independently Associated With Cardiovascular Disease and Mortality in Community-Dwelling Older Adults. J Am Coll Cardiol. 2012 Mar;59(12):1101-9.

81. Katagiri M, Takahashi M, Doi K, Myojo M, Kiyosue A, Ando J, et al. Serum neutrophil gelatinase-associated lipocalin concentration reflects severity of coronary artery disease in patients without heart failure and chronic kidney disease. Heart Vessels. 2016 Oct 1;31(10):1595-602.

82. Wu G, Li H, Fang Q, Jiang S, Zhang L, Zhang J, et al. Elevated circulating lipocalin-2 levels independently predict incident cardiovascular events in men in a population-based cohort. Arterioscler Thromb Vasc Biol. 2014 Nov;34(11):2457-64. 
83. Hasegawa M, Ishii J, Kitagawa F, Takahashi H, Sugiyama K, Tada M, et al. Plasma Neutrophil Gelatinase-Associated Lipocalin as a Predictor of Cardiovascular Events in Patients with Chronic Kidney Disease. BioMed Res Int. 2016;2016:1-7.

84. Solak Y, Yilmaz MI, Siriopol D, Saglam M, Unal HU, Yaman H, et al. Serum neutrophil gelatinase-associated lipocalin is associated with cardiovascular events in patients with chronic kidney disease. Int Urol Nephrol. 2015 Oct 26;47(12):1993-2001.

85. Martínez-Martínez E, Buonafine M, Boukhalfa I, Ibarrola J, Fernández-Celis A, Kolkhof P, et al. Aldosterone Target NGAL (Neutrophil Gelatinase-Associated Lipocalin) Is Involved in Cardiac Remodeling After Myocardial Infarction Through NFкB Pathway. Hypertens Dallas Tex 1979. 2017 Dec;70(6):1148-56.

86. Bauersachs J, Fraccarollo D. Mineralocorticoid Receptor-Dependent Adverse Remodeling After Myocardial Infarction Mediated by uNGALant Activation of NFкB. Hypertens Dallas Tex 1979. 2017 Dec;70(6):1080-1.

87. Sung HK, Chan YK, Han M, Jahng JWS, Song E, Danielson E, et al. Lipocalin-2 (NGAL) Attenuates Autophagy to Exacerbate Cardiac Apoptosis Induced by Myocardial Ischemia. J Cell Physiol. 2017 Aug;232(8):2125-34.

88. Eilenberg W, Stojkovic S, Kaider A, Kozakowski N, Domenig CM, Burghuber C, et al. NGAL and MMP-9/NGAL as biomarkers of plaque vulnerability and targets of statins in patients with carotid atherosclerosis. Clin Chem Lab Med. 2017 Nov 27;56(1):147-56.

89. Cheng L, Xing H, Mao X, Li L, Li X, Li Q. Lipocalin-2 Promotes M1 Macrophages Polarization in a Mouse Cardiac Ischaemia-Reperfusion Injury Model. Scand J Immunol. 2015 Jan 1;81(1):31-8.

90. Yang B, Fan P, Xu A, Lam KS, Berger T, Mak TW, et al. Improved functional recovery to I/R injury in hearts from lipocalin-2 deficiency mice: restoration of mitochondrial function and phospholipids remodeling. Am J Transl Res. 2012;4(1):60-71.

91. Folkesson M, Kazi M, Zhu C, Silveira A, Hemdahl A-L, Hamsten A, et al. Presence of NGAL/MMP-9 complexes in human abdominal aortic aneurysms. Thromb Haemost. 2007 Aug;98(2):427-33.

92. Tarín C, Fernandez-Garcia CE, Burillo E, Pastor-Vargas C, Llamas-Granda P, Castejón B, et al. Lipocalin-2 deficiency or blockade protects against aortic abdominal aneurysm development in mice. Cardiovasc Res. 2016 Aug 1;111(3):262-73.

93. Wang Y. Small lipid-binding proteins in regulating endothelial and vascular functions: focusing on adipocyte fatty acid binding protein and lipocalin-2: Lipid chaperones in cardiovascular diseases. Br J Pharmacol. 2012 Feb;165(3):603-21.

94. Tarjus A, Martínez-Martínez E, Amador C, Latouche C, El Moghrabi S, Berger T, et al. Neutrophil Gelatinase-Associated Lipocalin, a Novel Mineralocorticoid Biotarget, Mediates Vascular Profibrotic Effects of Mineralocorticoids. Hypertension. 2015;66(1):158166.

95. Song E, Fan P, Huang B, Deng H-B, Cheung BMY, Feletou M, et al. Deamidated Lipocalin-2 Induces Endothelial Dysfunction and Hypertension in Dietary Obese Mice. J Am Heart Assoc. 2014 Apr 10;3(2):e000837-e000837.

96. Law IKM, Xu A, Lam KSL, Berger T, Mak TW, Vanhoutte PM, et al. Lipocalin-2 Deficiency Attenuates Insulin Resistance Associated With Aging and Obesity. Diabetes. 2010 Apr 1;59(4):872-82.

97. Liu JT, Song E, Xu A, Berger T, Mak TW, Tse H-F, et al. Lipocalin-2 deficiency prevents endothelial dysfunction associated with dietary obesity: role of cytochrome P450 2C inhibition: Lipocalin-2 and endothelial dysfunction. Br J Pharmacol. 2012 Jan;165(2):520-31. 98. Jankowska EA, von Haehling S, Anker SD, Macdougall IC, Ponikowski P. Iron deficiency and heart failure: diagnostic dilemmas and therapeutic perspectives. Eur Heart J. 2013 Mar 1;34(11):816-29. 
99. Lapice E, Masulli M, Vaccaro O. Iron Deficiency and Cardiovascular Disease: An Updated Review of the Evidence. Curr Atheroscler Rep. 2013 Oct 1;15(10):358.

100. Xu G, Ahn J, Chang S, Eguchi M, Ogier A, Han S, et al. Lipocalin-2 induces cardiomyocyte apoptosis by increasing intracellular iron accumulation. J Biol Chem. 2012;287(7):4808-4817.

101. Lindberg S, Jensen JS, Hoffmann S, Iversen AZ, Pedersen SH, Biering-Sørensen T, et al. Plasma Neutrophil Gelatinase-Associated Lipocalin Reflects Both Inflammation and Kidney Function in Patients with Myocardial Infarction. Cardiorenal Med. 2016 Feb 25;6(3):180-90.

102. Yigit IP, Celiker H, Dogukan A, Ilhan N, Gurel A, Ulu R, et al. Can serum NGAL levels be used as an inflammation marker on hemodialysis patients with permanent catheter? Ren Fail. 2015 Jan 2;37(1):77-82.

103. Han M, Li Y, Liu M, Li Y, Cong B. Renal neutrophil gelatinase associated lipocalin expression in lipopolysaccharide-induced acute kidney injury in the rat. BMC Nephrol. 2012 Jun 27;13:25.

104. Bonnemaison ML, Marks ES, Boesen EI. Interleukin-1 $\beta$ as a driver of renal NGAL production. Cytokine. 2017 Mar;91:38-43.

105. Shen F, Hu Z, Goswami J, Gaffen SL. Identification of Common Transcriptional Regulatory Elements in Interleukin-17 Target Genes. J Biol Chem. 2006 Aug 25;281(34):24138-48.

106. Zhao P, Elks CM, Stephens JM. The Induction of Lipocalin-2 Protein Expression in Vivo and in Vitro. J Biol Chem. 2014 Feb 28;289(9):5960-9.

107. Lee S, Kim J-H, Kim J-H, Seo J-W, Han H-S, Lee W-H, et al. Lipocalin-2 Is a Chemokine Inducer in the Central Nervous System: ROLE OF CHEMOKINE LIGAND 10 (CXCL10) IN LIPOCALIN-2-INDUCED CELL MIGRATION. J Biol Chem. 2011 Dec 23;286(51):43855-70.

108. Wang H-H, Wu M-M, Chan MWY, Pu Y-S, Chen C-J, Lee T-C. Long-term low-dose exposure of human urothelial cells to sodium arsenite activates lipocalin-2 via promoter hypomethylation. Arch Toxicol. 2014 Aug;88(8):1549-59.

109. Jang E, Lee S, Kim J-H, Kim J-H, Seo J-W, Lee W-H, et al. Secreted protein lipocalin-2 promotes microglial M1 polarization. FASEB J. 2013 Mar 1;27(3):1176-90.

110. Pitashny M, Schwartz N, Qing X, Hojaili B, Aranow C, Mackay M, et al. Urinary lipocalin-2 is associated with renal disease activity in human lupus nephritis. Arthritis Rheum. 2007 Jun;56(6):1894-903.

111. Shashidharamurthy R, Machiah D, Aitken JD, Putty K, Srinivasan G, Chassaing B, et al. Differential Role of Lipocalin 2 During Immune Complex-Mediated Acute and Chronic Inflammation in Mice: Lipocalin 2 During Immune Complex-Mediated Inflammation. Arthritis Rheum. 2013 Apr;65(4):1064-73.

112. Gilet A, Zou F, Boumenir M, Frippiat J-P, Thornton SN, Lacolley P, et al. Aldosterone up-regulates MMP-9 and MMP-9/NGAL expression in human neutrophils through p38, ERK1/2 and PI3K pathways. Exp Cell Res. 2015 Feb;331(1):152-63.

113. Park CG, Choi KM. Lipocalin-2, A-FABP and inflammatory markers in relation to flow-mediated vasodilatation in patients with essential hypertension. Clin Exp Hypertens. 2014 Nov;36(7):478-83.

114. Ong K-L, Tso AWK, Cherny SS, Sham P-C, Lam T-H, Lam KSL, et al. Role of Genetic Variants in the Gene Encoding Lipocalin-2 in the Development of Elevated Blood Pressure. Clin Exp Hypertens. 2011 Nov;33(7):484-91.

115. Nakamura T, Mizuno S. The discovery of Hepatocyte Growth Factor (HGF) and its significance for cell biology, life sciences and clinical medicine. Proc Jpn Acad Ser B. 2010;86(6):588-610. 
116. Fan D, Takawale A, Lee J, Kassiri Z. Cardiac fibroblasts, fibrosis and extracellular matrix remodeling in heart disease. Fibrogenesis Tissue Repair. 2012;5(1):15.

117. Mebratu Y, Tesfaigzi Y. How ERK1/2 activation controls cell proliferation and cell death: Is subcellular localization the answer? Cell Cycle. 2009;8(8):1168-1175.

118. Ko SH, Jung J, Kim Y-J, Kim JS, Kim JM, others. Bacteroides fragilis enterotoxin upregulates lipocalin-2 expression in intestinal epithelial cells. Lab Invest. 2013;93(4):384. 119. Mao S, Jiang T, Shang G, Wu Z, Zhang N. Increased expression of neutrophil gelatinase-associated lipocalin receptor by interleukin- $1 \beta$ in human mesangial cells via MAPK/ERK activation. Int J Mol Med. 2011 Apr;27(4):555-60.

120. Ding G, Fang J, Tong S, Qu L, Jiang H, Ding Q, et al. Over-expression of lipocalin 2 promotes cell migration and invasion through activating ERK signaling to increase SLUG expression in prostate cancer: LCN2/ERK/SLUG Axis Promotes PCa Aggression. The Prostate. 2015 Jun;75(9):957-68.

121. Lawrence T. The Nuclear Factor NF- B Pathway in Inflammation. Cold Spring Harb Perspect Biol. 2009 Dec 1;1(6):a001651-a001651.

122. van der Heiden K, Cuhlmann S, Luong LA, Zakkar M, Evans PC. Role of nuclear factor $\kappa \mathrm{B}$ in cardiovascular health and disease. Clin Sci. 2010 May 1;118(10):593-605.

123. Harrison DG, Guzik TJ, Lob HE, Madhur MS, Marvar PJ, Thabet SR, et al. Inflammation, Immunity, and Hypertension. Hypertension. 2011 Feb 1;57(2):132-40. 124. Montecucco F, Liberale L, Bonaventura A, Vecchiè A, Dallegri F, Carbone F. The Role of Inflammation in Cardiovascular Outcome. Curr Atheroscler Rep. 2017 Mar;19(3):11. 125. Imig JD, Ryan MJ. Immune and inflammatory role in renal disease. Compr Physiol. 2013 Apr;3(2):957-76.

126. Candido S, Maestro R, Polesel J, Catania A, Maira F, Signorelli SS, et al. Roles of neutrophil gelatinase-associated lipocalin (NGAL) in human cancer. Oncotarget. 2014;5(6):1576.

127. Xiao X, Yeoh BS, Vijay-Kumar M. Lipocalin 2: An Emerging Player in Iron Homeostasis and Inflammation. Annu Rev Nutr. 2017 Aug 21;37:103-30. 


\section{FIGURES}

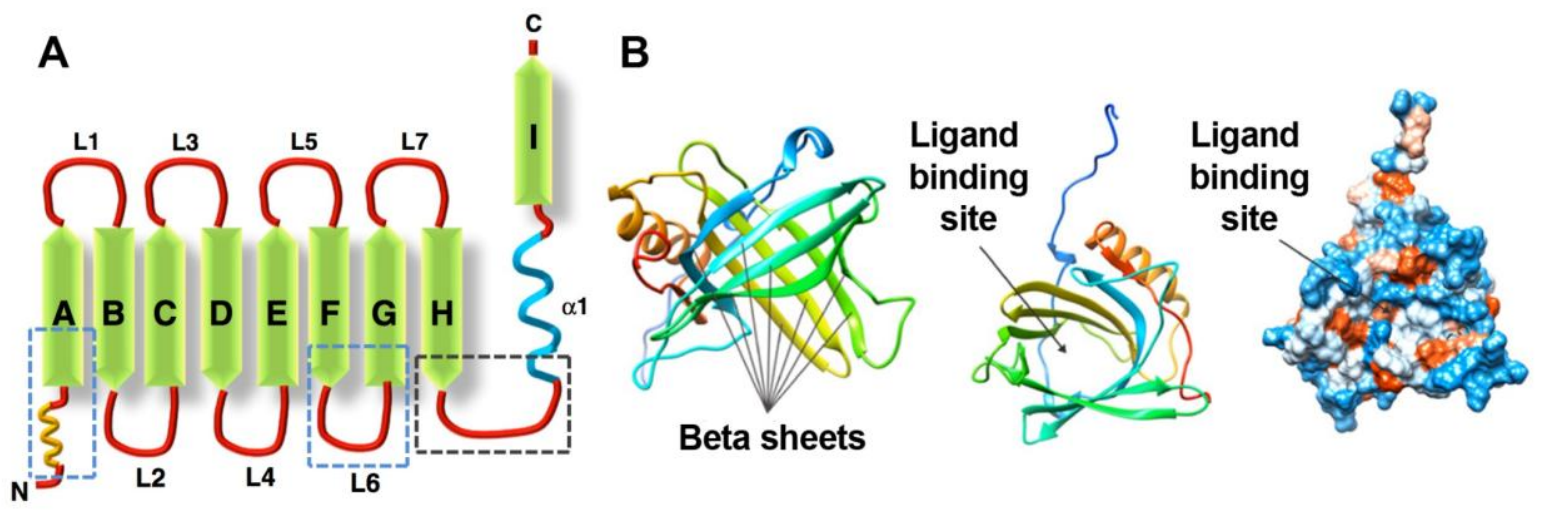

Figure 1 - Schematic structure of lipocalins

(A) Schematic representation of the lipocalin fold. The areas framed in blue correspond to the domains structurally preserved within the lipocalin family and the region framed in black corresponds to a domain showing significant conservation in amino acid sequence. Adapted from Chakraborty et al. 2012 (17). (B) Tridimensional structure of lipocalins. Adapted from Candido et al. 2014 (126). 
A

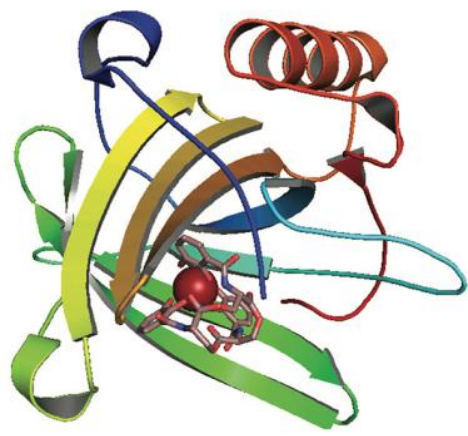

B

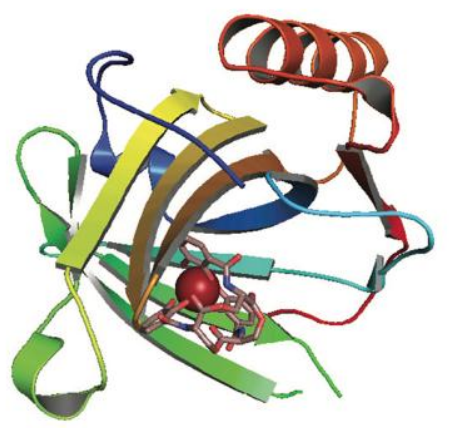

C

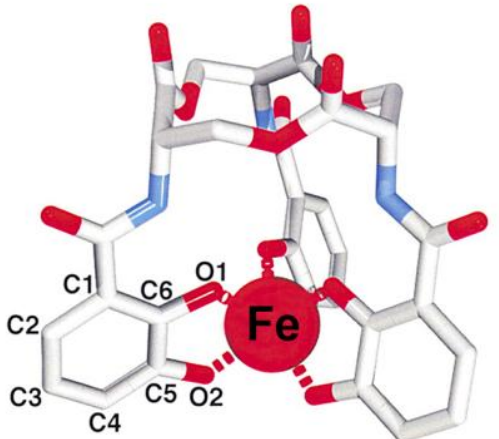

Figure 2 - Three-dimensional structure of the NGAL-siderophore-iron complex

Three-dimensional representation of NGAL in humans (A) and mice (B). The red sphere in the center corresponds to an iron atom and the surrounding structure corresponds to a siderophore. Adapted from Xiao et al. 2017 (127). (C) Representation of a siderophoreiron complex to which NGAL can bind. The atoms are identified by their color: $\mathrm{C}$ in grey, $\mathrm{N}$ in blue, $\mathrm{O}$ in red. The red sphere corresponds to the iron atom in the center of the siderophore. Adapted from Goetz et al. 2002 (13). 

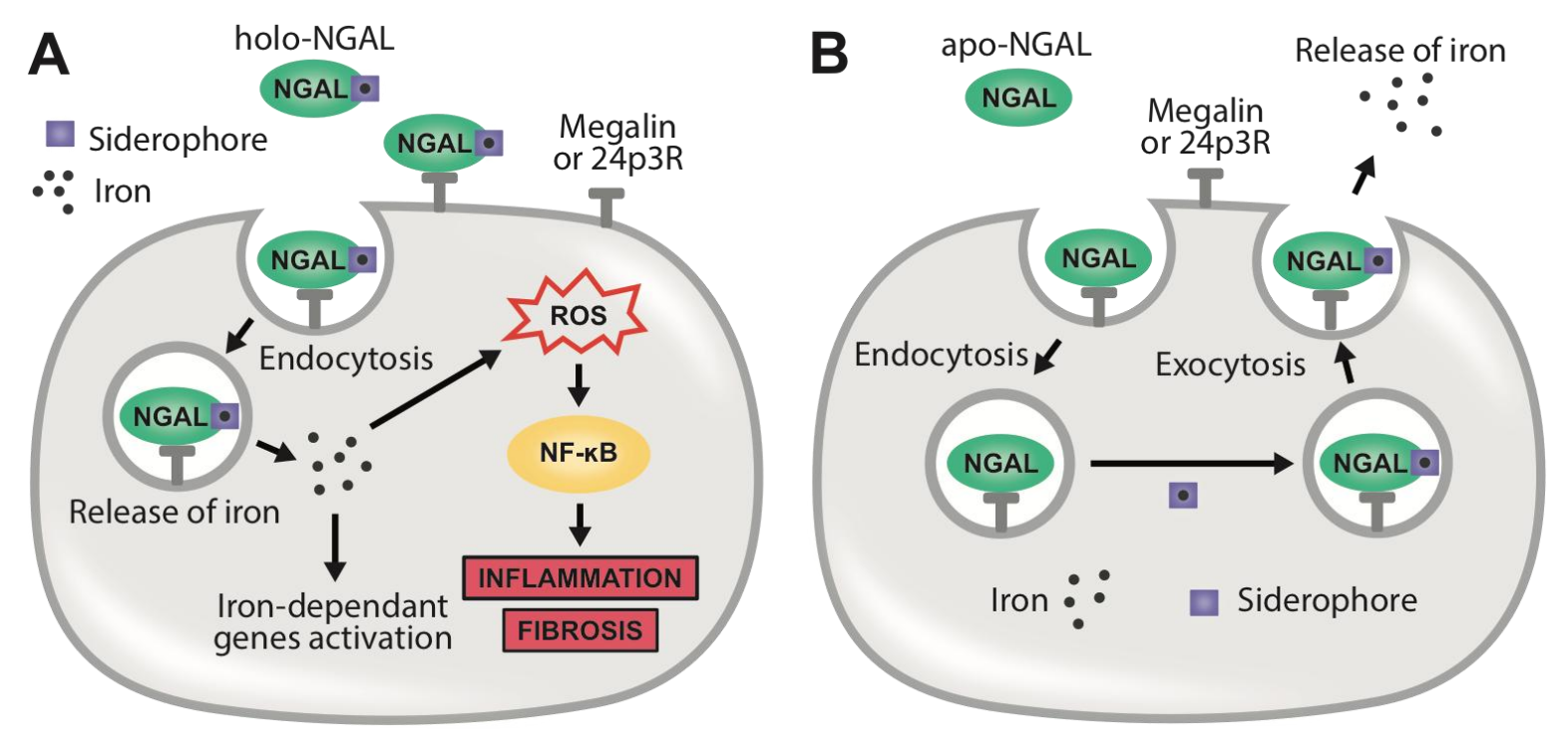

Figure 3 - Role of NGAL in iron trafficking

(A) Importation of iron into the cell. NGAL bound to an iron-coupled siderophore (holoNGAL) is endocytosed in the cell thanks to its membrane receptor (Megalin or 24p3R) thus allowing the release of iron into the cytoplasm. The increase in cytoplasmic iron levels will induce the expression of iron-dependent genes and promote oxidative stress which, in turn, activates the NF-kB pathway, known to be involved in inflammatory and fibrotic mechanisms. ROS: Reactive Oxygen Species. (B) Exportation of the iron out of the cell. Free NGAL (apo-NGAL) is endocytosed into the cell where it binds to an iron-coupled siderophore. It is then exocytosed out of the cell, thus allowing the release of iron in the extracellular medium and the diminution of the intracellular iron stock. 


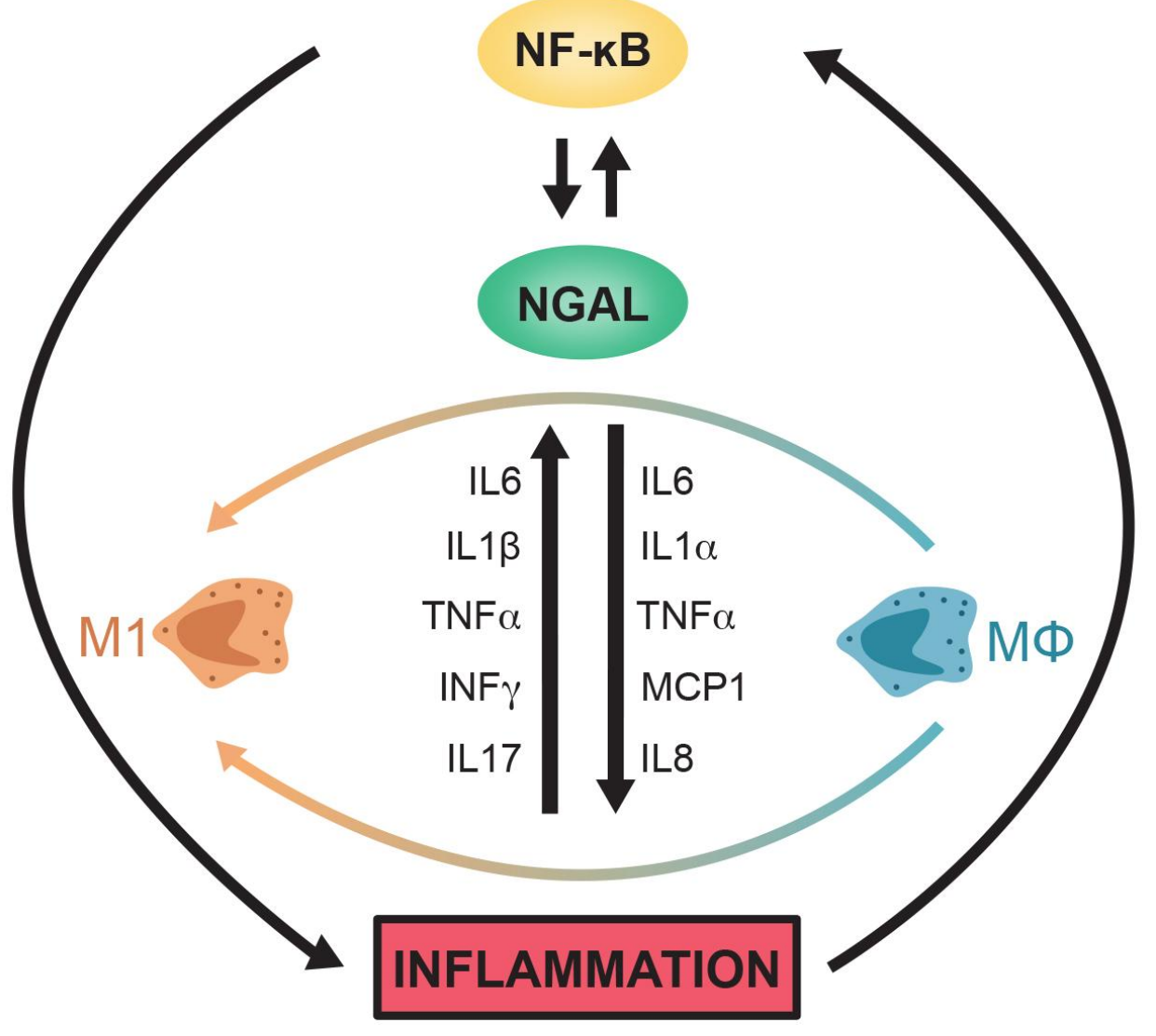

Figure 4 - Implication of NGAL in a pro-inflammatory amplification loop

NGAL expression is induced by several pro-inflammatory cytokines as well as NF- $\mathrm{B}$ pathway activation. Conversely, NGAL has pro-inflammatory effects, inducing the expression of various pro-inflammatory cytokines and activation of the NF- $\mathrm{B}$ pathway. NGAL is also involved in the polarization of macrophages towards the pro-inflammatory phenotype M1. MФ : Macrophage, M1 : Pro-inflammatory M1 macrophage 